\title{
Sharing Tips with Strangers: Exploiting Gift Culture in Computer Gaming
}

\author{
CHUEN-TSAI SUN, Ph.D., ${ }^{1}$ HOLIN LIN, Ph.D., ${ }^{2}$ and CHHENG HONG HO, M.A. ${ }^{3}$
}

\begin{abstract}
The aim of this study was to look at motivations behind altruistic behavior in virtual communities by studying the sharing of game tips by experienced gamers. We examine several possible motivations (pure altruism, generalized reciprocity, and reputation) and qualitatively analyze tip types in terms of usefulness, visibility, and skill level. We found that in games that do not support a "performance stage" for skill demonstration, players often share game tips as a strategy to attract attention. To a certain degree, reciprocity can be used to explain small favor exchanges, but earning social reputation is often a much stronger motivating factor.
\end{abstract}

\section{INTRODUCTION}

A GAME TIP is a piece of information that helps the recipient understand a specific game component or overcome a barrier. Tips known as "full walkthrough" give comprehensive instructions for solving puzzles, manipulating fighting skills, or finding recipes that help players overcome challenges they encounter in a storyline. Another type, called "treasure maps," reveals the locations of hidden valuables for players to collect. Taiwanese players often make use of context-dependent tips known as "drama-play translation guides," which help them overcome language barriers when playing Japanese- or English-language versions of games.

Many players use game bulletin boards to exchange tips. Since tips entail responses to specific queries, most of them are accurately answered. The first example is from a bulletin board for The Legend of Zelda: The Ocarina of Time $^{19}$ :

Inquiry: Help!! Where can I learn the sun's song that allows me to reverse day and night?
Answer: Go to the village in the direction of Death Mountain, then try to find a secret path along the wall of the graveyard. The way to enter the graveyard is to play Zelda's Lullaby, which you just learned from Princess Zelda.

When these kinds of tips are shared with complete strangers, a strong altruistic motive exists. As several senior gamers told us, small favors are considered a standard part of game culture, expressed as "I help because I was helped by others before." We also observed that some players devote large amounts of time to creating free, Internet-based "full walkthroughs" that other people test, refine, and publish off-line for profit. Because this behavior has economic value, and since the beneficiaries are mainly strangers, we felt that this phenomenon requires analysis and explanation.

Pure altruism (representing a culture that does not expect payback of any sort) is the first of three possible explanations for such behavior in virtual communities. The second is reciprocal exchange, in which tip providers are viewed as rational individuals who expect similar paybacks from other mem-

${ }^{1}$ Department of Computer Science, National Chiao Tung University, Hsinchu, Taiwan.

2Department of Sociology, National Taiwan University, Taipei, Taiwan.

3Joint Graduate Programme in Communication \& Culture, York \& Ryerson University, Toronto, Canada. 
bers of their community. The third depicts sharing behavior as a means of earning social reputation.

In this study we will use three analytical dimensions to investigate these interpretations: the usefulness of the provided service (measured by degree of need); visibility (since a free service must be recognized for its provider to receive recognition); and the skill level of the service (the easier it is, the greater the number of players who are capable of providing it). We assumed that the more altruistic the motive, the more likely that usefulness or community needs are the main force behind an action. From another perspective, the less visible the act, the more likely it is based on altruism. From the perspective of social-reputation theory, visibility is the primary concern of individuals who care the most about earning social appreciation and approval. Sometimes the desire for visibility is so strong that service (in this case, tip) quality is sacrificed.

Since the focus of reciprocal exchange is on mutual awareness of an implicit give-and-take relationship, community members should have the same (or very similar) capacity for providing mutually useful services. In contrast, behaviors enacted in the name of pure altruism or recognition are representative of people who are in more powerful or advantageous positions (as measured by resources or skills) than their fellow community members. For this reason, we utilized the "skill level" concept as our third dimension for analyzing tips.

\section{LITERATURE REVIEW}

Several attempts have been made to explain why certain people help others with no guaranteed payback. The term generalized reciprocity describes a system in which assistance given to one person is reciprocated by someone who is not the original recipient of the favor. ${ }^{26} \mathrm{~A}$ prime example in the digital era is the electronic posting of announcements, queries, and responses-one of the most common activities of online groups. ${ }^{10,13}$ However, according to Desouza's ${ }^{8}$ reading of the literature, most research on virtual communities is focused on their informational aspects, at the expense of studying altruistic exchanges of knowledge in professional communities.

Ever since the 1954 publication of his original work on gift exchange, Marcel Mauss ${ }^{16}$ and his followers have described gifts as being different from commodities because they are not contingent upon future reciprocation. Using the example of inter- tribal presentations, Mauss showed how gift exchanges create human interrelationships. Several decades later, Cheal ${ }^{6}$ described gift economies as transaction systems that serve interpersonal representations and realizations beyond explanations based on political economy or exchange theory. While these anthropological insights serve as accurate descriptions of how gifts create social bonds in the physical world, it remains to be seen if the same theory can be applied to exchanges in virtual worlds.

If we consider Internet-distributed game tips as gifts, recipient anonymity becomes an important issue. Kollock, ${ }^{14}$ in his review of Carrier and Bell's ${ }^{5}$ ideal types of gift economy, argues that the gifting concept cannot be used to explain why we help anonymous strangers on the Internet. Instead, he suggests that such contributions should be considered public goods rather than commodities or gifts. Two questions remain: (a) Why do participants perform acts that seem unprofitable on the surface? (b) Why do they devote themselves to offering information with no promise of reciprocity?

Davenport ${ }^{7}$ categorized knowledge-sharing rewards as pure altruism, reciprocity, and reputation. The first emphasizes the intrinsic nature of altruism-helping strangers according to a belief system. ${ }^{28}$ When discussing open-source communities, some researchers argue that individual self-empowerment and cultural distinctiveness are adequate motivators for explaining altruistic behavior. ${ }^{12,25}$

Other researchers have focused on extrinsic incentives for altruistic behavior. In Social Exchange: The Two Traditions, Ekeh ${ }^{9}$ commented on contrasts between economic models that describe exchange in strict terms of economic or utilitarian value and social models that describe exchange in terms of symbolic value. According to the economic model, rational reciprocity is of primary concern, with equity theorists emphasizing the rational grounds that individuals use to evaluate the input/output ratios of certain behaviors. ${ }^{27}$ Other theorists emphasize rational calculations of perceived contribution benefits. 13,22

The tradition that Ekeh" referred to as the "social model" suggests that expertise can be exchanged for status, respect, compliance, or obligation, ${ }^{4,18}$ with social approval being the main reward for acts of compassion or generosity. ${ }^{4}$ In a similar manner, Goldhaber ${ }^{11}$ analyzed cyberspace economies, and Raymond ${ }^{23}$ analyzed open-source communities as "reputation games," with both assuming that prestige has greater value in virtual than in real world gift cultures. 


\section{METHODS}

We chose role-playing games (RPGs) as our focus based on our belief that their complex scenarios and requirements are more likely to generate requests for assistance. As in the rest of the world, role-playing games are the most popular genre in Taiwan. Two-thirds (67.6\%) of our survey respondents identified RPGs as their favorite game format, with action games a distant second (9.5\%). Results from a separate survey conducted by Taiwan's largest gaming website (Bahamut) of its members showed that $83.9 \%$ chose RPGs as one of their three favorite game types.

The three primary sources of the data used in this study were

1. An online survey using an electronic questionnaire placed on our website. We posted an invitation to participate in the survey on Bahamut. In 1 week (September 6-15, 2003), we collected 861 usable questionnaires, from which we organized demographic information and data on behaviors and preferences from a broad range of gamers.

2. Printed information, including articles and messages posted on game-related bulletin boards and discussion forums between May and August of 2003. The number of daily postings ranged between a dozen to more than 100 per game board, depending on the importance of recent events in a specific game environment. The majority of postings were specific questions about solving game problems and their responses. Full walkthroughs usually appeared a couple of days after the debut appearance of a new game. Combined, these postings allowed us to establish a thick description of everyday game-playing activities.

3. Interviews with 15 experienced gamers who frequently contributed tips of various types. Although all were actively involved in gamerelated tip behavior, some did not view themselves as game tip providers, based on a commonly held belief in game communities that only full walkthroughs should be considered true game tips. In other situations, tip-providers often described themselves as "merely answering questions and providing help for those who need it." All of our interviewees were males between the ages of 19 and 28. The majority said that they had started playing computer games in early childhood.
Potential interviewees were chosen from the pool of electronic survey respondents. We focused on those who described themselves as "actively and frequently sharing gaming experiences with others" and who indicated a willingness to be interviewed. Game-related bulletin boards were used to identify the contributors of game tips that had been collected and held in Bahamut archives. ${ }^{1}$ We then used a simple snowball sampling method-that is, interviewees identified via the first two methods were asked to refer one more participant to our study. Detailed descriptions are given in Appendix A.

\section{RESULTS AND DISCUSSION}

Our primary findings were (a) a combination of quick queries/answers and exchanges of small favors can be considered a part of game culture that is driven by reciprocity, and (b) serious tip production is primarily driven by the contributor's pursuit of social approval. Tip types are highly context-dependent and varied according to the gaming situation. When a game environment provides a performance stage (complete with onlookers), altruistic behavior takes the form of small favors that are focused on general reciprocity or reinforcing existing social relationships. When no stage is available, gamers devote much more energy to producing serious tips to attract attention from gaming communities.

To distinguish between "useful" and "visible" altruistic behaviors, we compared two major RPG platforms: console games (e.g., those played on Gamecube, PlayStation, or Xbox) and massive multiplayer online (MMO) games. MMORPG games consist of small societies, with almost all achievements and individual performances being visible during interactions among large numbers of characters. In contrast, console RPG players only interact with a console interface-usually alone, but sometimes with a small number of friends. A common console RPG situation consists of a few friends playing different games or different stages of the same game. In other words, console RPGs lack immediate, large-scale performance stages.

\section{Finding a stage}

Our console game-centered interviewees claimed that all gamers primarily want to play with per-

${ }^{1}$ The Bahamut game website does not provide contact information for authors who post articles privately. 
sonal friends and acquaintances, but may hesitate if they think they cannot perform well in front of them. Survey responses confirm this point: players who are not being watched by friends still enjoy being watched by outsiders. ${ }^{2}$ Both experienced and good players tend to have friends who play together (thus allowing them to act as consultants), while mediocre and novice players tend to join game-playing activities because their friends are already playing. Serious gamers often keep detailed records of their games to share with friends, to answer questions about their gaming experiences, or to write game guides.

With few exceptions, we found that experienced console gamers have no performance stages, while online RPG players have more avenues for earning fame and acknowledgement in the form of such public methods as ranking systems. We also observed that experienced gamers have a tendency to play alone (a phenomenon we will discuss in a later section) and tend to choose games based on magazine reviews or television advertisements rather than recommendations from friends. ${ }^{3}$ Console game players are more likely to have strong individual preferences for certain game types; even when they are in the same room with friends, they usually play separate games. When these players have major breakthroughs, they are less likely to have someone in their social circles to acknowledge their accomplishments, thus requiring a different type of achievement demonstration. One way to gain recognition is to contribute tips, which not only expresses the provider's willingness to help others, but also shows that the provider has overcome a barrier. Several interviewees expressed a preference for discussing gaming problems (and sharing accomplishments) with online co-hobbyists rather than off-line friends. Most importantly, they reported gaining a sense of social approval from their tip contributions.

We also observed that tips distributed freely to anonymous recipients are credited to specific authors. In published game guides, originators are usually acknowledged by having their names and contact addresses printed. One interviewee (the owner of a game website) told us that he consciously avoids publishing excerpts from other writers' guides on his site because he does not want to lure too many visitors from the original writers' websites. In short, tip providers are identifiable, almost everybody in a gaming community knows who they are, and in many cases their offline identities are also known.

\section{Selecting the right tip: speed matters}

To earn acknowledgement and appreciation, tips need to be useful. However, usefulness is insufficient when tip givers step on stage to show off their achievements, since doing so spotlights the additional factors of visibility and skill level. We identified four tip categories on console RPG boards, analyzed their usefulness and visibility to their respective gaming communities, and determined their connections to a player's tip production. The categories were question-and-answers (Q\&As), full walkthroughs, secret treasure maps, and dramaplay translation guides. Examples and screenshots are shown in Appendix B.

Q\&As consist of the short and to-the-point questions and responses described above. Topics range from the very general (e.g., "I don't know how to proceed") to the very specific (e.g., "How can I get extra treasure from the main path?"). The most useful and clearly written tips are eventually collected and presented as frequently asked questions (FAQs).

Full walkthroughs are comprehensive, step-bystep instructions designed to lead players through a single route to the final game goal. Recipients are given the necessary information to overcome all barriers-how to solve puzzles, manipulate fighting skills, and find correct recipes. Initial full walkthroughs are usually created by aggressive players of new games. Other players tend to use them as general references, preferring to read them in detail only when they become very confused or frustrated.

Secret treasures are common tools used by game designers to divert players' attention from accomplishing the main goals of an adventure. Secret treasure maps pinpoint their locations and frequently contain clues on how to retrieve them. The information is usually considered a bonus for players who have already achieved primary game goals.

\footnotetext{
${ }^{2}$ We observed that the percentage of respondents who strongly agreed with the statement "I do not want to be watched when playing" declined when the player's expertise increased. We also found that $24.5 \%$ of all beginners preferred not being watched while only $10.6 \%$ of all experienced players expressed the same preference.

${ }^{3}$ We were surprised to find that $62.3 \%$ of the experienced gamer respondents rely on information from television or magazines, while only $17.8 \%$ of the beginners relied on the same sources for choosing games. Furthermore, $57.8 \%$ of the beginners stated that they choose games based on recommendations from friends.
} 


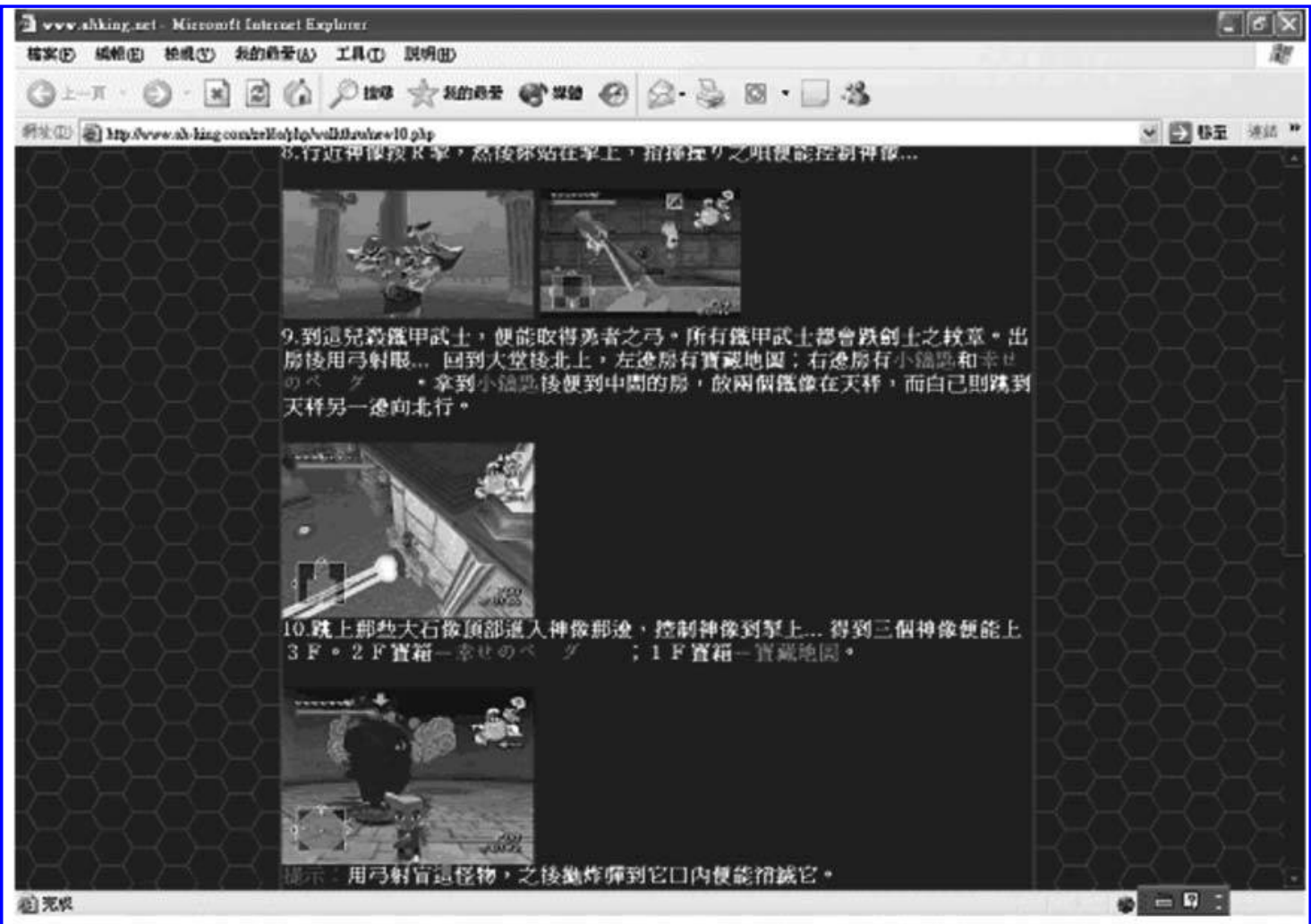

FIG. 1. Walkthroughs: step-by-step solutions.

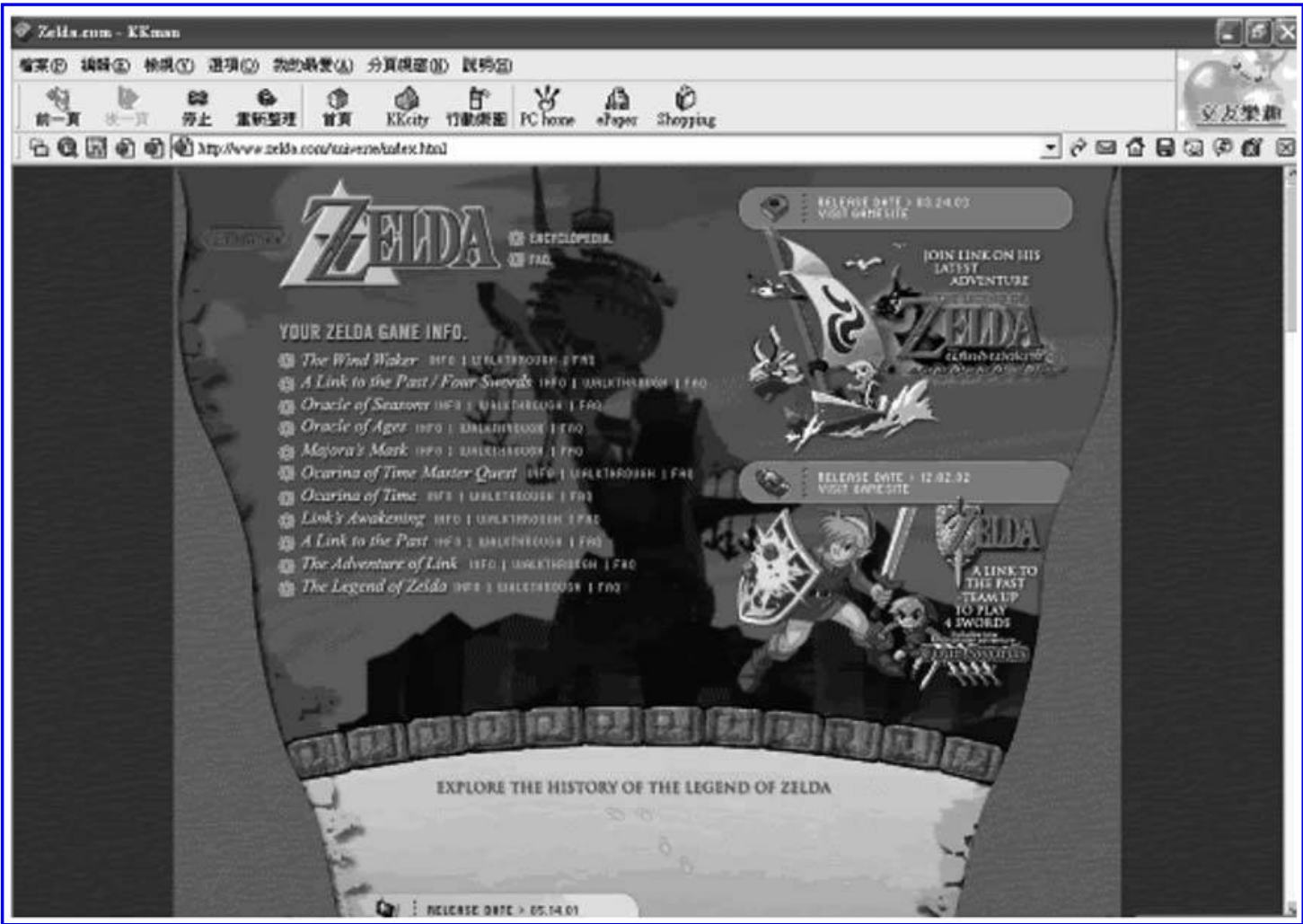

FIG. 2. Official English walkthrough for The Legend of Zelda. 


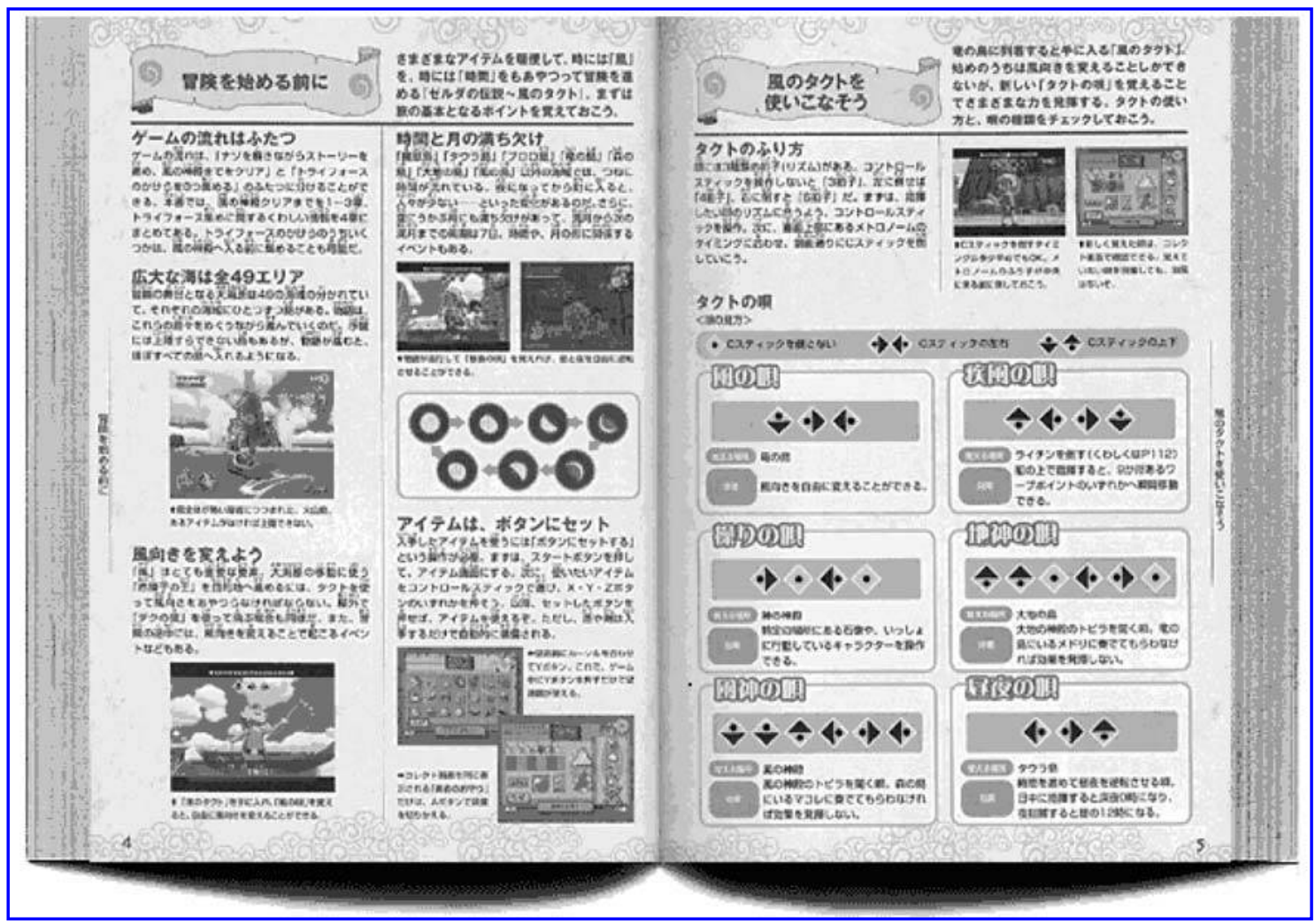

FIG. 3. Official Japanese walkthrough for The Legend of Zelda.

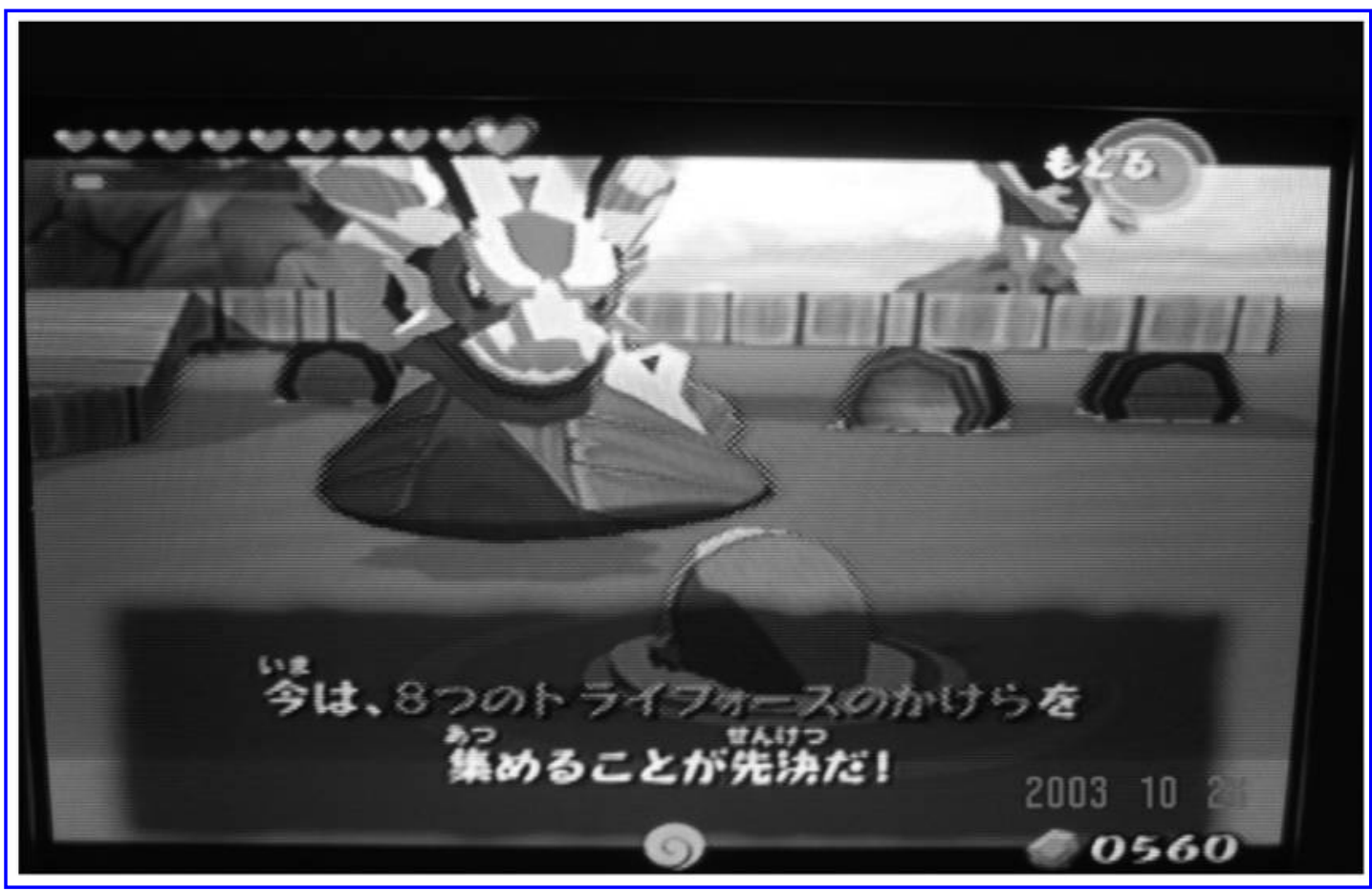

FIG. 4. Japanese game dialogues. 
Drama-play translation guides (which provide translations of on-screen information and conversations) are useful for games with foreign language interfaces. They are very helpful in terms of a game's more subtle aspects-for instance, finding clues embedded in dialogues about alternative ways to proceed, places to visit or inspect, and objects that may be useful for completing later tasks in the game. Note that drama-play translation guides are not simply screen-by-screen translations; publishers also add contextual descriptions to make the dialogues comprehensible in the contexts of re-created storylines.

Characteristics of the four tip types (based on combined data sources) and their corresponding amounts are shown in Table 1. By comparing entries and analyzing tradeoffs made by tip providers, it is possible to identify reasons for their producing (or not producing) certain tip types. For Q\&As, we noticed that queries on console game bulletin boards tend to be short and specific and answers to the point and useful. These information fragments are exchanged among many players at the same skill level. Players who know the answer to a query do not hesitate to give it, and they expect others to do the same when they raise questions later on. Only those tips that are added to FAQs gain visibility. We therefore suggest that $Q \& A s$ represent the practice of general reciprocity.

Several interviewees described drama-play translation guides as the most desirable tip category, since many players benefit from the efforts of the few individuals who write them. Most of our interviewees said it was not very difficult to translate English versions of clues and dialogues into Chinese, perhaps because many Taiwanese players are required to study English starting in middle school. We failed to find many complete dramaplay translation guides, and instead observed a large number of translated game fragments, reflecting individual translators' opinions that some episodes were more interesting than others.

In summary, the majority of console RPG tips were in the form of answers to short questions or full walkthroughs. A possible explanation is that the skill level required for drama-play translations is very high. Persistence is a key characteristic in successful treasure map location, and a complete drama-play translation implies that the provider has overcome all barriers to performing that task. But the writing of a drama-play translation guide does not provide the same sense of reward as solving game-related challenges. Once a translation is posted, its author may be appreciated for having good linguistic, but not good gaming, skills-the latter associated with publishing a strategy guide. Experienced players can write a full walkthrough in one long evening session, which gives them the potential to earn appreciation, admiration, and visibility for being the first to publish a guide for a new game. Thus, the smaller numbers of treasure maps and drama-play translations also suggest that visibility is a critical factor in the efforts of players to solve problems and to share their expertise with others.

In summary, social approval is a driving force behind tip production, with speed an important secondary factor. Players need to finish a game (or several runs of the same game) in order to identify tips for sharing. This explains why a number of Taiwanese players buy the Japanese versions of new games as soon as they can, thinking that they cannot afford to wait for the English version in spite their superior English skills. We also observed Taiwanese gamers playing a Korean game called Ragnarok Online on overseas game servers prior to its launch date in Taiwan, presumably to earn social approval by being the first to provide tips to fellow players.

\section{Exchanging small favors in existing social networks: MMORPGs}

Online RPGs provide very different gaming experiences than console RPGs. They are more likely to have fluid storylines that change according to player actions and interactions-a challenge to anyone who is motivated to write a walkthrough.

Table 1. Console Game Tip Types: Characteristics and Quantities

\begin{tabular}{llccl}
\hline Tip-type & QEAs & $\begin{array}{c}\text { Full } \\
\text { walkthroughs }\end{array}$ & Treasure maps & $\begin{array}{c}\text { Drama-play } \\
\text { translations }\end{array}$ \\
\hline Usefulness & Medium & High & Medium & Very high \\
Skill level & Medium & High & Medium & High \\
Visibility & Medium & High & Medium & Medium \\
Quantity & Large & Large & Small & Small \\
\hline
\end{tabular}


Junior players can find both information and access to new friends, which for many is reason enough to avoid using published guides. In Taiwan, most MMORPGs have become localized, with many produced and played in Chinese. Furthermore, newbies and less experienced players have little trouble getting help from trusted sources-mostly their closest friends. Combined, these factors drastically reduce the market for drama-play guides. Furthermore, since online games provide immediate environments for experienced players to show off their skills, there is less of a need to find external stages (e.g., chat rooms and websites dedicated to specific games) for acknowledgement. ${ }^{4}$ This is an important distinction between online RPG tip cultures and their console counterparts in Taiwan.

This does not imply a lack of need for online gaming help-tipping behavior still exists in online RPG communities, but in different form. For example, players may receive virtual bottles of water from strangers when needed, or receive directions (or even escorts) to locations that they can't find on their own. Another type of helping behavior is pledging loans of valuable equipment to fellow players for castle sieges. Tipping situations can be distinguished by skill level: giving water is an example of "small favors" that are fragmented, spontaneous, and at a lower level, while castle sieges require organization and planning at a much higher skill level. A summary of these points is offered in Table 2.

We also observed roughly equal numbers of Q\&As on online RPG and console RPG boards, but with differences in terms of content. The most popular topic for online Q\&As is treasure maps; as a gift to "outsiders," this kind of sharing is mainly done for demonstrating achievement-similar to our finding for console players. In the world of online games, sources of treasure usually exist for short time periods and are subject to chance discov- ery, therefore it is especially useful when one friend tells another how to locate them. If the treasure is already gone, there is an element of boastfulness attached to announcing its location on a BBS.

Small favors (e.g., helping a stranger who is in bad health or under attack by a monster) are very common in the gaming world, but visibility is usually low because only characters who are present at the moment the favor is given can witness the event. We therefore view small favors as examples of general reciprocity. As one interviewee told us, "a bottle of water is no big deal." This observation confirms McGuire's ${ }^{17}$ assertion that individuals tend to underestimate the value of help they provide relative to help they receive. The result is a sense of indebtedness that encourages helping others-friends and strangers alike.

Helping fellow members improve their fighting skills or loaning expensive equipment in support of castle sieges are not small favors. These types of high skill-level behaviors entail risk, suggesting an element of pure altruism. However, we found that in Taiwan, online RPGs have a strong off-line social component, with game guilds consisting of classmates and close friends. ${ }^{15}$ One interviewee told us that when his group planned a castle siege, all members agreed to meet online at the same time (from five separate Internet cafes) in order to act as a collective body. In other words, online gaming tips are frequently used to reinforce existing organizations and interpersonal relationships, with mutual favors taking on the status of obligations.

\section{Impact on game play and management}

As mentioned in an earlier section, the Japanese versions of console games are usually imported to Taiwan much faster than their English counterparts. Consequently, most Taiwanese RPG players prefer playing with Japanese versions even though

Table 2. Online Game Tip Types: Characteristics And Quantities

\begin{tabular}{lllcc}
\hline Tip-type & QEAs & Small favors & $\begin{array}{c}\text { Helping team } \\
\text { members }\end{array}$ & $\begin{array}{c}\text { Full walkthroughs, } \\
\text { drama-play } \\
\text { translations }\end{array}$ \\
\hline Usefulness & Medium & Medium & High & Do not exist \\
Skill level & Medium & Low & High & \\
Visibility & Medium & Low & High & \\
Quantity & Large & Medium & Large & \\
\hline
\end{tabular}

${ }^{4}$ For example, character ranks are visible and onlookers can witness game achievements in real time. 
they are required to study English in junior and senior high school. We found that game tips reinforce this trend, since English-version players report that it is more difficult to get help from Englishlanguage than from Japanese-language websites and bulletin boards. Most of the questions we observed concerned the Japanese names (or nicknames) of places or objects. When the same questions arise for English names, most players are unable - or unwilling - to reply. Obviously, this has a direct effect on local tip cultures.

The availability of gaming tips encourages customers to buy a particular game, since they know that they can get help; the existence of tip sources implies the popularity or quality of a game. Even though many game companies publish their own "official" walkthroughs, this phenomenon cannot be viewed as a marketing strategy. For obvious reasons, companies do not publish tips until a certain period has passed following the launching of a game. In many ways, official guides serve as collector's items and souvenirs rather than useful tools for serious players, who are more likely to rely on tips. To prevent players from losing interest after overcoming all possible obstacles (with or without the help of walkthrough guides), many game companies offer awards for taking different paths to achieve identical game goals. 5 These bonus awards are not revealed in the main storyline; only those players who persist after achieving the primary goal the first time are eligible to collect them, usually with help in the form of tips.

As expected, players have complex feelings about walkthroughs. Instead of constantly hitting a key to move on to the next screen of a guide, the majority of players use walkthroughs in a calculated way, and they seem to acknowledge that learning clues and keys too quickly can erode their sense of satisfaction and challenge. This factor affects the mindset of gamers as well as the efforts of tip contributors, who understand that giving away too much information too soon might actually damage their reputations. We were a bit surprised to find that the most successful console game tip contributors had good writing skills and the discipline to share tips a few at a time.

In console games, we noticed that many players compete with each other to be the first to deliver a full walkthrough; the mix of competition and sharing increases gaming satisfaction. But online games have longer operational periods and flexibility (i.e., gaming elements can be adjusted), therefore tipproviders have greater potential to dialogue with game designers as well as each other, meaning that the impacts of their actions are not limited to fellow players.

It is clear that tipping behavior combines features of digital media and social interaction. It penetrates game play, reaches the fertile soil of gaming situation and context, and exerts a strong impact on game culture construction. Investigators need to take into consideration not only game factors such as "do tips help or hurt the fun of the game?" but also social factors such as "does anyone play alone?"

\section{CONCLUSION}

We found some significant differences from our comparison of tip-sharing behaviors between console and online RPG players. Since online RPGs offer immediate performance stages and audiences, fewer gamers are willing to write tips and share them on a public game board. Due to the lack of performance stages, experienced console RPG players need to contribute their game tips in order to create stages outside the game. Through sharing, console RPG tip providers seek the approval or recognition of community members in order to establish their reputations. In this situation, tip provision and skill demonstration are activities that are easily observed by fellow players.

We investigated the usefulness, visibility, and skill level of game tips to determine the strongest motivations behind tip writing and sharing, and found that tips are a potent means of attracting attention from players who appreciate the tip provider's skill and achievement. Accordingly, rapid and frequent recognition appears to be much more important than altruism. This explains (at least in part) why tip providers prefer one tip type to others.

The results also indicate that digital game playing transcends a simple interactive relationship between a player and a machine. Devotion to a game is not determined simply by the amount of fun provided; social interaction among players in the gaming community plays an essential role in gaming construction and fun. To a certain degree it is possible to argue that no one plays alone (even those gamers who play single-player games without onlookers), since score bulletin boards and tipsharing are central to gaming communities.

\footnotetext{
5In Legend of Zelda: The Wind Waker, second-time players are given access to a "picto box" that allows them to take color photos of any character and turn them into collectable prints.
} 
APPENDIX A

List of interviewee/participants

\begin{tabular}{cccll}
\hline $\begin{array}{c}\text { Tip- } \\
\text { provider }\end{array}$ & $\begin{array}{c}\text { Being } \\
\text { reached bya }\end{array}$ & Age & \multicolumn{1}{c}{$\begin{array}{c}\text { Educational status/ } \\
\text { occupation }\end{array}$} & Favorite game type \\
\hline A & Method 2 & 23 & University student & Console games \\
B & Method 1 & 22 & University student & Console games \\
C & Method 1 & 20 & University student & Console/online games \\
D & Method 2 & 22 & University student & Console games \\
E & Method 1 & 21 & University student & Console gnline games \\
F & Method 2 & 22 & University student & Console/online games \\
G & Method 2 & 19 & Junior high school drop-out/unemployed & Console games \\
H & Method 3 & 22 & University student & Console/online games \\
I & Method 3 & 17 & Vocational high school student & Console/online games \\
J & Method 1 & 20 & Technology college student & Console/online games \\
K & Method 1 & 28 & Computer engineer & Console/online games \\
L & Method 3 & 26 & Vocational high school graduate/ & \\
& & & computer engineer & \\
\hline
\end{tabular}

Method 1: respondents of electronic questionnaire; Method 2: frequent game tip-contributors on Bahamut game website; Method 3: interviewees from snowball sampling. For details please see the Methods section of this article.

\section{APPENDIX B}

\section{Examples of three tip categories}

1. Walkthroughs. Figure 1 is an example of a walkthrough web page in Chinese. The following excerpt, from the strategy guide for The Legend of Zelda: The Ocarina of Time, ${ }^{19}$ exemplifies the goalminded, procedural context of most walkthroughs:

Enter Lost Woods at the north end of Kakiri Forest and follow these steps to get out of the maze: upright-up-up-left-up. You will enter Sacred Forest Meadow, where you will meet Saria, who will teach you "Saria's Song." If you enter the room to the left of the entrance, you can play Saria's Song to the clown, who will reward you with a heart piece. Later, when you play this song for the King of Goron, he will give you a bracelet that allows you to pick up bomb flowers.

The publication of walkthroughs for this game made it even more popular. Nintendo subsequently published its own walkthroughs (with game stories, screenshots, maps, and advice on playing methods) as a collector's item for players. Figures 2 and 3 are examples of the official walkthroughs for The Legend of Zelda in English and Japanese, respectively.
2. Secret treasure maps. The following example is from the official Nintendo website for The Legend of Zelda ${ }^{21}$ :

To find all 36 heart pieces that can increase your total life energy: at Lon Lon Luck, enter the storage shed in the Lon Lon Ranch. Move a large box that is blocking a small hole that holds the heart piece. At Rooted Out, blow up a tree on the north side of Lon Lon Ranch to reveal a secret grotto that holds a heart piece.

3. Drama-play translation guides. Figure 4 shows a screen from the Japanese version of The Legend of Zelda. The following excerpt is taken verbatim from a translation guide:

[On the seashore]

Red Lion King: You must find that Valoo and get a treasure - the gem of fire-from him.

Go to see the Rito tribe, and they will tell you how to find the Valoo.

Wait! There is one more thing! This is the wind waker. People use this baton to play music in order to pray. In the past, using it would let people borrow magic power from God, but I have no idea whether it works or not. However, I still think this will be helpful to you, you should learn how to use it... 


\section{ACKNOWLEDGMENTS}

This research was supported by the National Science Council, Republic of China, grant number NSC 93-2412-H-002-008. This is a revised version of a paper entitled "Game Tips as Gifts" presented at the 2003 Digital Games Research Conference held in Utrecht, The Netherlands.

\section{REFERENCES}

1. Bagozzi, R.P. (1975). Marketing as exchange. Journal of Marketing 38:77-81.

2. Bell, D. (1991). Modes of exchange: gift and commodity. Journal of Socio-Economics 20:155-167.

3. Berkowitz, L., \& Daniels, L.R. (1964). Affecting the salience of the social responsibility norm: effect of past help on the response to dependency relationships. Journal of Abnormal and Social Psychology 68: 275-281.

4. Blau, P.M. (1964). Exchange and power in social life. New York: Wiley.

5. Carrier, J. (1991). Gifts, commodities, and social relations: a Maussian view of exchange. Sociological Forum 6:119-136.

6. Cheal, D. (1988). The gift economy. London: Routledge.

7. Davenport, T.H., \& Prusak, L. (1998). Working knowledge: how organizations manage what they know. Boston: Havard Business School Press.

8. Desouza, K. (2002). An investigation into socially altruistic knowledge communities. Presented at the 2002 Annual Conference of Midwest Academy of Management, Indianapolis

9. Ekeh, P. (1974). Social exchange theory: the two traditions. Cambrige, MA: Harvard University Press.

10. Finholt, T., \& Sproull, L.S. (1990). Electronic groups at work. Organizational Science 1:41-64.

11. Goldhaber, M.K. (1997). The attention economy and the Net. First Monday. Available at: www.firstmonday.dk/issues/issue2_4/index.html. Accessed July $15,2006$.

12. Himanen, P. (2001). The hacker ethic, and the spirit of the information age. New York: Random House.

13. Kettinger, W.J., \& Grover, V. (1997). The use of computer-mediated communication in an interorganizational context. Decision Sciences 28:513-535.

14. Kollock, P. (1999). The economies of online cooperation: gifts and public goods in cyberspace. In: Smith, M.A., Kollock, P. (eds.), Communities in cyberspace. New York: Routledge, pp. 220-239.

15. Lin, H., Sun, C.-T., \& Tinn, H.-H. (2003). Social enclaves and cooperation in online gaming. Presented at the Digital Games Research Conference 2003, Utrecht, The Netherlands.

16. Mauss, M. (1954). The gift: forms and functions of exchange in archaic societies. New York: Norton.

17. McGuire, A.M. (2003). "It was nothing"—extending evolutionary models of altruism by two social cognitive biases in judgments of the costs and benefits of helping. Social Cognition 21:363-394.

18. Mesch, D.J., Tschirhart, M., Perry, J.L. et al. (1998). Altruists or egoist? Retention in stipended service. Nonprofit Management \& Leadership 9:3-21.

19. Nintendo. (1998). The Legend of Zelda: the ocarina of time. Redmond, WA: Nintendo.

20. Nintendo. (2003a). The Legend of Zelda: the wind waker. Redmond, WA: Nintendo.

21. Nintendo. (2003b). Official website of "The Legend of Zelda." Available at: www.zelda.com.

22. Payne, J.W. (1982). Contingent decision behavior. Psychological Bulletin 92:382-402.

23. Raymond, E.S. (1998). Homesteading the noosphere. First Monday. Available at: www.firstmonday.dk/issues/issue3_10/raymond/index.html. Accessed July 15,2006

24. Sun, C.-T, Lin, H., \& Ho, C.-H. (2003). Game tips as gifts: social interactions and rational calculations in computer gaming. Presented at the Digital Games Research Conference 2003, Utrecht, The Netherlands.

25. Thompson, N. (2000). Reboot! How Linux and opensource development could change the way we get things done. Washington Monthly March 2000.

26. Titmuss, R.M. (1971). The gift relationship: from human blood to social policy. New York: Pantheon.

27. Walster, E., Walster, W.G., \& Berscheid, E. (1978). Equity: theory and research. Boston: Allyn and Bacon.

28. Wasko, M.M., \& Faraj, S. (2000). It is what one does: why people participate and help others in electronic communities of practice. Journal of Strategic Information Systems 9:155-173.

Address reprint requests to: Dr. Chuen-Tsai Sun Department of Computer Science National Chiao Tung University Hsinchu, Taiwan 30050

E-mail: ctsun@cis.nctu.edu.tw

Professor Holin Lin Department of Sociology National Taiwan University Taipei, Taiwan

E-mail: holin@ntu.edu.tw 


\section{This article has been cited by:}

1. Yoonhyuk Jung, Boryung Ju, Lisl Zach. 2012. Influence of Interfaces on Novice Users' Performance in Social Virtual Worlds. Journal of the Korean Society for information Management 29:4, 7-23. [CrossRef]

2. Chuen-Tsai Sun, Dai-Yi Wang, Hui-Ling Chan. 2011. How digital scaffolds in games direct problem-solving behaviors. Computers \& Education 57:3, 2118-2125. [CrossRef]

3. Mika Lehdonvirta, Vili Lehdonvirta, Akira Baba. 2011. Prosocial behaviour in avatar-mediated interaction: the influence of character gender on material versus emotional help-giving. On the Horizon 19:3, 165-173. [CrossRef]

4. Gráinne Kirwan. 2010. Cyberpsychology. The Irish Journal of Psychology 31:1-2, 69-84. [CrossRef]

5. Maria Frostling-Henningsson. 2009. First-Person Shooter Games as a Way of Connecting to People: "Brothers in Blood". CyberPsychology \& Behavior 12:5, 557-562. [Abstract] [Full Text PDF] [Full Text PDF with Links]

6. S OREG, O NOV. 2008. Exploring motivations for contributing to open source initiatives: The roles of contribution context and personal values. Computers in Human Bebavior 24:5, 2055-2073. [CrossRef] 